\title{
Outcome of COVID-19 Infection in Cancer Patients
} in Pune

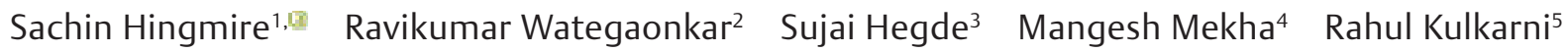 \\ Ashwin Rajbhoj ${ }^{6} \quad$ Chetan Deshmukh ${ }^{1} \quad$ Padmaj Kulkarni ${ }^{1} \quad$ Tushar Patil $^{5}$ Gajanan Kanitkar ${ }^{3}$ \\ Pankaj Wanjarkhedkar ${ }^{1,0}$ Anupama Mane ${ }^{4} \quad$ Kamlesh Bokil $^{7} \quad$ Amit Parasnis $^{1}$ Jayant Gawande ${ }^{2}$ \\ Jatin Bhatia ${ }^{8}$ Bhagyashree Khaladkar ${ }^{1}$ Nagesh Sirsath ${ }^{9}$ Sameer Melinkeri ${ }^{1}$ Bhalchandra Kashyapi ${ }^{1}$ \\ Rakesh Kumar Agrawal ${ }^{2}$ Anushree Prabhakaran ${ }^{1}$ Isha Desai ${ }^{10} \quad$ Dhananjay Kelkar $^{1}$
}

\footnotetext{
${ }^{1}$ Department of Oncology, Deenanath Mangeshkar Hospital \& Research Center, Pune, Maharashtra, India

2Department of Oncology, Aditya Birla Memorial Hospital, Pune, Maharashtra, India

${ }^{3}$ Department of Oncology, Ruby Hall Clinic, Pune, Maharashtra, India

${ }^{4}$ Department of Oncology, Jehangir Hospital, Pune, Maharashtra, India

${ }^{5}$ Department of Oncology, Sahyadri Superspecialty Hospital, Pune,

Maharashtra, India

${ }^{6}$ Department of Oncology, KEM Hospital, Pune, Maharashtra, India

${ }^{7}$ Dwidal Nursing Home, Pune, Maharashtra, India
}

\author{
Address for correspondence Dr. Sachin Hingmire, Department \\ of Oncology, Deenanath Mangeshkar Hospital, Pune 411004, \\ Maharashtra, India (e-mail: sshingmire@yahoo.com).
${ }^{8}$ Department of Oncology, Jupiter Hospital, Pune, Maharashtra, India ${ }^{9}$ Department of Oncology, Inlaks \& Budhrani Hospital, Pune, Maharashtra, India
${ }^{10}$ Department of Medicine, Deenanath Mangeshkar Hospital \& Research Center, Pune, Maharashtra, India

\section{South Asian J Cancer 2021;10:23-27.}

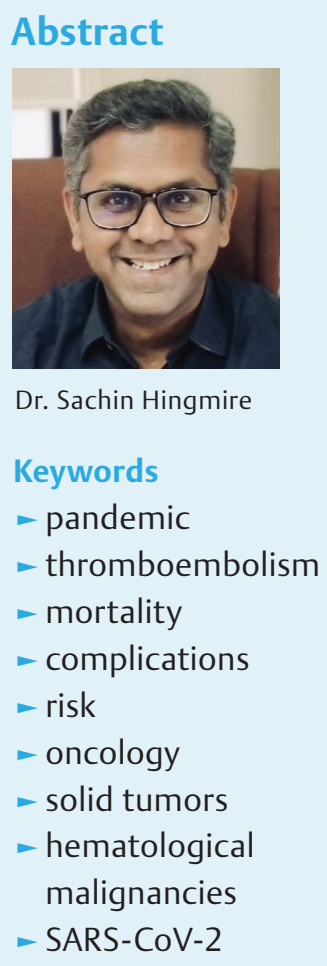

Introduction We document our data on the course of the coronavirus disease 2019 (COVID-19) infection in cancer patients in an attempt to help optimize their management in India and globally.

Material and Methods Between February 2020 and January 2021, participating oncologists from Pune (members of the Oncology Group of Pune) documented effect of COVID-19 infection in their cancer patients. Binomial logistic regression analysis as well as correlation analysis was done using Pearson Chi-square test to determine significance of clinical factors.

Results A total of 29 oncologists from 20 hospitals contributed their data involving 147 cancer patients who developed COVID-19 infections. COVID-19 infection resulted in higher deaths (likelihood ratio of 4.4) amongst patients with hematological malignancies $(12 / 44=27.2 \%)$ as compared with those with solid tumors $(13 / 90=14.4 \%$, $p=0.030)$. Patients with uncontrolled or progressive cancer $(11 / 34=32.4 \%)$ when they got infected with COVID-19 had higher mortality as compared with patients whose cancer was under control $(14 / 113=12.4 \% ; p=0.020)$. Complication of thromboembolic episodes (seen in eight patients; $5.4 \%$ cases) was associated with higher risk (25.6 times) of death (five-eighths; $62.5 \%$ ) as compared with those who did not develop it $(20 / 139 ; 14.4 \% ; p<0.001)$.
DOI https://doi.org/10.1055/s-0041-1731910 ISSN 2278-330X

How to cite this article: Hingmire $S$, Wategaonkar R, Hegde $S$, et al. Outcome of COVID-19 Infection in Cancer Patients in Pune. South Asian J Cancer 2021;10(1):23-27. (c) 2021. MedIntel Services Pvt Ltd.

This is an open access article published by Thieme under the terms of the Creative Commons Attribution-NonDerivative-NonCommercial-License, permitting copying and reproduction so long as the original work is given appropriate credit. Contents may not be used for commercial purposes, or adapted, remixed, transformed or built upon. (https://creativecommons.org/licenses/by-nc-nd/4.0/).

Thieme Medical and Scientific Publishers Private Ltd A-12, Second Floor, Sector -2, NOIDA -201301, India 
Discussion Patients with cancer should be advised to take strict precautions to reduce the risk of being infected with COVID-19. They should also be given priority for COVID-19 vaccination. If infected with COVID-19, patients with hematological malignancy and uncontrolled cancer are at higher risk of morbidity and mortality. When they are being treated (OPD or inpatient basis), additional precautions are necessary to ensure their exposure to potential COVID-19 virus is minimized. If they get infected with COVID-19, they should be given aggressive treatment to prevent complications, especially thromboembolic episodes. If they develop any thromboembolic complication, their risk of dying are significantly higher, and management should be modified accordingly.

\section{Introduction}

As the coronavirus disease 2019 (COVID-19) pandemic continues to baffle the world, we are facing new characteristics, changing mutations and surrounding circumstances that continue to teach us about the severe acute respiratory syndrome coronavirus 2 (SARS-CoV-2 virus). ${ }^{1-3}$ Pune, a city in Maharashtra has been a hotspot during this pandemic.

A lot of conflicting data and opinions have been put forth in scientific literature regarding the effect of COVID-19, especially amongst cancer patients. ${ }^{4-6}$ We therefore decided to document some of the features of this viral infection amongst our cancer patients. Our objective was to document the course of the COVID-19 infection in cancer patients and whether any characteristic correlated with outcome. We hoped that the analysis of our data will allow us to optimize management of COVID-19 infection amongst cancer patient in India and globally.

\section{Material and Methods}

Member Oncologists of the Oncology Group of Pune decided to collaborate and collectively analyze their real-world experience of cancer patients who had developed COVID-19 infection. This study was conducted over 1year (February 2020 to January 2021). Participating oncologists provided their anonymous data using a specifically designed online data collection form. The data was then tabulated. Binomial logistic regression analysis was performed to ascertain the effects of age, gender, stage, hematological versus solid tumors, treatments received, the status of cancer, and thromboembolic complications with respect to the outcomes of COVID-19 infection. Correlation analysis was done using Pearson Chi-square test

\section{Results}

A total of 29 oncologists from 20 cancer centers participated in the study. Their data included 147 patients, of which 75 were females and 72 males. Their age ranged from 18 to 83 years, with a median of 60 years. The initial diagnosis of cancer was made between 1997 and 2020.
The cancer types are shown in - Table 1. Breast cancer was the commonest diagnosis amongst the group. Solid tumors were seen in 105 (71\%) cases and 42 (29\%) patients had hematological malignancies.

Of the 147 cancer patients who got infected with COVID-19, 20 were in stage $1 ; 31$ were in stage 2; 36 in stage 3; and 52 in stage 4 (in the eight patients with acute leukemia, staging was not applicable).

On doing correlation analysis with Pearson Chi-square test, the malignancy group was found to be significantly associated with COVID-related deaths with higher deaths (likelihood ratio of 4.4) in hematological malignancies (12/44 $=27.2 \%)$ as compared with solid tumors $(13 / 90=14.4 \%$, $p=0.030)$.

Amongst the 147 patients, 95 were on active treatment; another 17 had completed their treatment in the last 6 months; 27 had completed their treatment more than 6 months ago; and nine had not received any anticancer treatment. Their oncology disease status included 34 with progressive disease, 55 with responding cancer, and 59 in complete remission.

Once diagnosed as COVID-19 positive, these patients were treated at 28 COVID-19 designated treatment centers. At initial presentation for COVID-19, 20 patients were asymptomatic; 64 had mild symptoms; 34 had moderate symptoms; and 30 had severe symptoms (including the requirement of ventilation). Their details are shown in - Table 2.

Amongst the COVID-19 asymptomatic cases, four were in stage 1 , seven in stage 2 , six in stage 3 and two in stage 4 . (one acute leukemia, stage NA). In the mildly symptomatic group, 10 in stage 1,12 in stage 2,16 in stage 3, and 20 in stage 4 (five with acute leukemia, Stage NA). Those with moderate symptoms included four in stage 1 , eight in stage 2, eight in stage 3 , and 12 in stage 4 (one acute leukemia, stage NA). In the group with severe symptoms, two were in stage 1 , four in stage 2 , six in stage 3 , and 18 in stage 4 (one with acute leukemia, stage NA) (-Table 3).

Correlating outcomes of COVID-19 with the status of the cancer, the results are show in - Table 4.

The current status of cancer was found to be significantly associated with COVID-19 outcome. Patients having 
Table 1 Cancer types amongst COVID-19 positive cases

\begin{tabular}{|l|l|l|}
\hline Sr. no. & Cancer type & No. of cases \\
\hline 1 & Breast & 40 \\
\hline 2 & NHL & 18 \\
\hline 3 & CRC & 14 \\
\hline 4 & SCCHN & 13 \\
\hline 5 & MM & 11 \\
\hline 6 & Acute Leukemia & 8 \\
\hline 7 & Ovary & 6 \\
\hline 8 & Chronic leukemia & 5 \\
\hline 9 & STS & 4 \\
\hline 10 & Lung & 3 \\
\hline 11 & Prostate & 3 \\
\hline 12 & Pancreatic & 3 \\
\hline 13 & Endometrial & 3 \\
\hline 14 & Esophagus & 3 \\
\hline 15 & Others & 13 \\
\hline & Total & 147 \\
\hline
\end{tabular}

Abbreviations: CRC, colorectal cancer; MM, multiple myeloma; NHL, non-Hodgkin lymphoma; SCCHN, squamous cell carcinoma of the head and neck; STS, soft-tissue sarcoma.

Table 2 Severity of COVID-19 features at presentation and outcome

\begin{tabular}{|l|l|l|l|}
\hline Sr. no. & $\begin{array}{l}\text { Severity of } \\
\text { COVID-19 }\end{array}$ & $\begin{array}{l}\text { No of } \\
\text { cases }\end{array}$ & No of deaths \\
\hline 1 & None & 20 & 00 \\
\hline 2 & Mild & 64 & 00 \\
\hline 3 & Moderate & 33 & 02 \\
\hline 4 & Severe & 30 & 23 \\
\hline
\end{tabular}

Table 3 Outcome of COVID-19 and status of anticancer treatment

\begin{tabular}{|l|l|l|l|}
\hline Sr. no. & Statue of anticancer Rx & Alive & Dead (\%) \\
\hline 1 & Active & 76 & $19(20 \%)$ \\
\hline 2 & Completed within 6 mo & 16 & $2(11 \%)$ \\
\hline 3 & $\begin{array}{l}\text { Completed more than 6 mo } \\
\text { ago }\end{array}$ & 22 & $3(12 \%)$ \\
\hline 4 & No anticancer Rx received & 8 & $1(11 \%)$ \\
\hline Total & & 122 & $25(17 \%)$ \\
\hline
\end{tabular}

Table 4 Status of cancer and outcome of COVID-19

\begin{tabular}{|l|l|l|l|}
\hline Sr. no. & Status of cancer & Alive & Dead (\%) \\
\hline 1 & Active and PD & 23 & $11(32 \%)$ \\
\hline 2 & Active and responding & 47 & $7(13 \%)$ \\
\hline 3 & In CR & 52 & $7(12 \%)$ \\
\hline Total & & 122 & $25(17 \%)$ \\
\hline
\end{tabular}

Abbreviations: COVID-19, coronavirus disease 2019; CR, colorectal cancer; PD, programmed death.

uncontrolled malignancy $(11 / 34=32.4 \%)$ at the time of COVID infection had higher mortality (likelihood ratio $=5.4$ ) as compared with controlled malignancy $(14 / 113=12.4 \%, p=0.020)$.

Thromboembolic episodes were seen in a total of eight (5.4\%) cases, five of whom $(62.5 \%)$ died and three recovered. ${ }^{7}$ This is in contrast with $20(14.4 \%)$ deaths in patients without thromboembolic complications. Statistical analysis shows that those who developed thromboembolic complications had 25.6 times (95\% CI: 4.3-142.1) higher risk of death (likelihood ratio of $8.9, p<0.001$ ).

Interestingly, the deaths correlated with the incidence of COVID-19 positivity amongst the cancer patients (maximum

Table 5 Correlation of nine predictive variables with respect to outcome of COVID-19 infection amongst cancer patients in Pune

\begin{tabular}{|l|l|l|l|l|l|l|l|l|l|}
\hline Predictive variables & B & S.E. & Wald & df & Sig. & Exp (B) & \multicolumn{2}{|c|}{$95 \%$ CI for EXP(B) } \\
\hline & & & & & & & Lower \\
\hline Gender & 0.475 & 0.529 & 0.806 & 1 & 0.369 & 1.608 & 0.570 & 4.535 \\
\hline Malignancy_group & 0.867 & 0.528 & 2.697 & 1 & 0.101 & 2.380 & 0.845 & 6.702 \\
\hline Treatment_status & 0.424 & 0.371 & 1.311 & 1 & 0.252 & 0.654 & 0.316 & 1.353 \\
\hline Last_cancer_treatment & 0.278 & 0.213 & 1.703 & 1 & 0.192 & 1.320 & 0.870 & 2.003 \\
\hline Current_status_cancer & 0.594 & 0.379 & 2.461 & 1 & 0.117 & 0.552 & 0.263 & 1.160 \\
\hline $\begin{array}{l}\text { Thromboembolic_complica- } \\
\text { tions_COVID19 }\end{array}$ & 3.232 & 0.903 & 12.816 & 1 & 0.000 & 0.039 & 0.007 & 0.232 \\
\hline Age & 0.038 & 0.021 & 3.351 & 1 & 0.067 & 0.963 & 0.925 & 1.003 \\
\hline Stage & 0.129 & 0.324 & 0.158 & 1 & 0.691 & 0.879 & 0.466 & 1.660 \\
\hline Constant & 4.235 & 2.358 & 3.226 & 1 & 0.072 & 69.065 & \\
\hline
\end{tabular}

aVariable(s) entered on step 1: Gender, Malignancy_group, Treatment_status, Last_cancer_treatment, Current_status_cancer, Thromboembolic_Complications_COVID19, Age, Stage. 
in months of July, August, and September 2020); and is similar to the incidence of new COVID-19 positive cases in India; peaking in September 2020.,9

Overall, the logistic regression model was statistically significant, $\chi^{2}(9)=28.2, p<0.0005$. The model explained $29.0 \%$ (Nagelkerke $R^{2}$ ) of the variance in COVID-related deaths and correctly classified $83.0 \%$ of cases. Of the nine predictor variables, only thromboembolic complications were statistically significant (as shown in -Table 5 ).

\section{Discussion}

The COVID-19 pandemic is relentlessly affecting our world in a manner that we have failed to understand or predict. ${ }^{10}$ The hope that vaccination shall tame the monster was a premature celebration. ${ }^{11}$ Also vaccination studies had specifically excluded patients with cancer. So, the impact of COVID-19 on cancer patients remained an enigma.

It is now clear that cancer patients may have poorer outcome when infected with COVID-19., ${ }^{4,5}$ We have to simply glance at the overall mortality rate in India (1.2\%; total deaths $1,72,115$ when total incidence was $1,38,73,825)$; in United States (1.8\%; total deaths: 5,77,179 when total incidence was $3,20,70,840)$; and globally (2.2\%; total deaths $29,74,544$ when total incidence was $13,81,06,949)$ and compare with the mortality rate of $9.8 \%$ seen in the apex cancer hospital of India (Tata Memorial Hospital, Mumbai).1,12,13

Like in the general population, COVID-19 infection in cancer patients mimicked the chronological incidence as well as the age of patients ( - Fig. 1). It also affected cancer patients across the entire spectrum of solid tumors and hematological malignancies. However, COVID-19 infection resulted in higher death rate in patients with hematological malignancies $(12 / 44=27.2 \%)$ as compared with those with solid tumors $(13 / 90=14.4 \%, p=0.030)$.

Higher mortality was also seen amongst cancer patients whose malignancy remained uncontrolled when COVID-19 infection occurred $(11 / 34=32.4 \%$ vs. $14 / 113$ in patients with controlled malignancy; $p=0.020$ ).

The most significant factor from our data is the impact of thromboembolic episodes on outcome. They occurred in $8 / 147$ (5.4\%) cases, five of whom (62.5\%) died (as compared

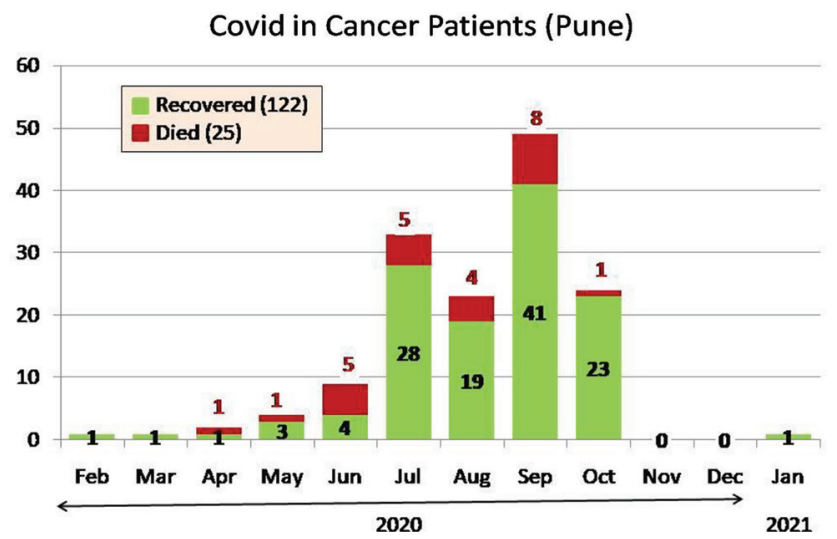

Fig. 1 Chronology of COVID-19 positivity amongst cancer patients. COVID-19, coronavirus disease 2019. with 20 [14.4\%] deaths in patients who did not develop thromboembolic complications; $p<0.001)$. Thus, development of thromboembolic complications was associated with 25.6 times (95\% CI: 4.3-142.1) higher risk of death.

It is well known that COVID-19 infected patients have a higher incidence of coagulopathy, disseminated intravascular coagulation, and venous thromboembolism (VTE). They appear to be in a prothrombotic state that can even lead to deep vein thrombosis, pulmonary embolism, and death. It is said to be triggered by endothelial damage, microvascular thrombosis, venous occlusion, and/or autoimmune phenomenon. Elevated blood D-dimer ( $>1.5 \mu \mathrm{g} / \mathrm{mL}$; normal range: $0.0-0.5 \mu \mathrm{g} / \mathrm{mL}$ ) has been shown to predict higher risk of VTE (sensitivity $85.0 \%$; specificity $88.5 \%$ ). D-dimer has the potential to also serve as a risk stratification tool in COVID-19. In fact, the International Society on Thrombosis and Haemostasis (ISTH), recommends that if any COVID-19 patient has D-dimer levels which are three to four-times higher than normal, such patients should be hospitalized even if they are asymptomatic. International Society on Thrombosis and Haemostasis as well as American Society of Hematology have published guidelines. They recommend that all patients (including non-critically ill) who require hospital admission for COVID-19 infection should receive pharmacologic thromboprophylaxis with LMWH, fondaparinux, or similar agents-unless there is increased bleeding risk..$^{14-17}$

Based on our data we suggest the following take home messages (-Table 6) for patients with cancer during the ongoing COVID-19 pandemic and especially when the second wave is overwhelming many parts of the world..$^{12,18-21}$

Table 6 Take home messages for optimized management of cancer patients during the ongoing COVID-19 pandemic

\begin{tabular}{|l|l|}
\hline Sr. no. & Message \\
\hline 1 & $\begin{array}{l}\text { Patients with cancer should take strict precautions to } \\
\text { reduce the risk of being infected with COVID-19. }\end{array}$ \\
\hline 2 & $\begin{array}{l}\text { Cancer patients should be given priority for COVID-19 } \\
\text { vaccination-as vulnerable patients. }\end{array}$ \\
\hline 3 & $\begin{array}{l}\text { If exposed or infected with COVID-19, cancer patients } \\
\text { should be considered at higher risk of morbidity and } \\
\text { mortality. }\end{array}$ \\
\hline 4 & $\begin{array}{l}\text { When cancer patients come to health care facilities to } \\
\text { undergo treatment (suggesting that their cancer is yet } \\
\text { to be controlled), additional precautions are necessary } \\
\text { to ensure their exposure to potential COVID-19 virus is } \\
\text { minimized. }\end{array}$ \\
\hline 5 & $\begin{array}{l}\text { Cancer patients with COVID-19 infections should be } \\
\text { treated aggressively to prevent development of any } \\
\text { thromboembolic complication. }\end{array}$ \\
\hline 6 & $\begin{array}{l}\text { If cancer patients with COVID-19 infections develop a } \\
\text { thromboembolic complication, their risk of dying are } \\
\text { significantly higher. }\end{array}$ \\
\hline 7 & $\begin{array}{l}\text { All patients (including noncritically ill) who require } \\
\text { hospital admission for COVID-19 infection should } \\
\text { receive pharmacologic thromboprophylaxis with } \\
\text { LMWH, fondaparinux, or similar agents-unless there is } \\
\text { increased bleeding risk. }\end{array}$ \\
\hline
\end{tabular}

Abbreviations: COVID-19, coronavirus disease 2019; LMWH, low molecular weight heparin. 
Conflict of Interest

None declared.

\section{References}

1 Worldometer. Coronavirus. Available at: https://www.worldometers.info/coronavirus/. Accessed April 14, 2021

2 Purvish P, Prashant M, Shyam A. Important COVID-19 updatenew life-threatening syndrome in pediatric patients? Int J Mol Immuno Oncol 2020;5(2):42-43

3 Parikh PM, Mehta P, Krishna MM, Babu GK. Clinical trials facing serious adverse events during the ongoing COVID-19 Pandemic. Indian J Med Paediatr Oncol 2020;41:127-131

4 Kuderer NM, Choueiri TK, Shah DP, et al; COVID-19 and Cancer Consortium. Clinical impact of COVID-19 on patients with cancer (CCC19): a cohort study. Lancet 2020;395(10241): 1907-1918

5 Liang W, Guan W, Chen R, et al. Cancer patients in SARS-CoV-2 infection: a nationwide analysis in China. Lancet Oncol 2020;21(3):335-337

6 Parikh PM, Bapna A, Krishna MV, Mehta P, Aggarwal S, Gulia A. COVID-19 testing in India in comparison to the rest of the world. If Indian testing strategy was replicated in the other top 15 COVID-19 affected countries in the world, the status would be startlingly different. Indian $\mathrm{J}$ Med Sci 2020;72(2):107-109

7 Ackermann M, Verleden SE, Kuehnel M, et al. Pulmonary vascular endothelialitis, thrombosis, and angiogenesis in COVID-19. N Engl J Med 2020;383(2):120-128

8 Parikh P. COVID-19 pandemic: contrast between SAARC countries and western world. 2020. Available at: https://www. m3india.in/contents/editor_pick/136721/covid-19-pandemic-contrast-between-saarc. Accessed April 12, 2020

9 Parikh P, Mehta P, Bansal S, et al. Protecting health-care professionals and workers (other than COVID-19 management facilities) from contamination during COVID-19 pandemic. Indian J Med Sci 2020;72:3-4

10 Mehta P, Parikh P, Aggarwal S, et al. Has India met this enemy before? From an eternal optimist's perspective: SARS-CoV-2. Indian J Med Sci 2020;72:8-12

11 Parikh P, Singh R. Hot race for COVID-19 vaccines-light at the end of the tunnel just got brighter. Int J Mol Immuno Oncol 2021;6(1):1-3
12 ESMO. Cancer Patient Management During the COVID-19 Pandemic. Available at: https://www.esmo.org/ guidelines/cancer-patient-management-during-the-covid19-pandemic. Accessed April 10, 2021

13 The Hindustan Times. Mumbai News. Available at: https:// www.hindustantimes.com/mumbai-news/covid-19-deathrate-among-mumbai-s-cancer-patients-stands-at-9-8-tatamemorial-hospital/story-vp6l1ppcX3pr2ju1cgMVqI.html. Accessed April 14, 2021

14 Ciceri F, Beretta L, Scandroglio AM, et al. Microvascular COVID-19 lung vessels obstructive thromboinflammatory syndrome (MicroCLOTS): an atypical acute respiratory distress syndrome working hypothesis. Crit Care Resusc 2020;22(2):95-97

15 Kollias A, Kyriakoulis KG, Dimakakos E, Poulakou G, Stergiou GS, Syrigos K. Thromboembolic risk and anticoagulant therapy in COVID-19 patients: emerging evidence and call for action. Br J Haematol 2020;189(5):846-847

16 Thachil J, Tang N, Gando S, et al. ISTH interim guidance on recognition and management of coagulopathy in COVID-19. Published: March 25, 2020. Available at: https://clotconnect.wpcomstaging.com/2020/03/26/ covid-19-and-coagulopathy-two-management-guidance-documents-for-health-care-professionals/. Accessed April 14, 2021

17 COVID-19 and VTE/Anticoagulation. Frequently asked questions. Available at: https://www.hematology.org/covid-19/ covid-19-and-vte-anticoagulation. Accessed April 10, 2021

18 Tartarone A, Lerose R. COVID-19 and cancer care: what do international guidelines say? Med Oncol 2020;37(9):80

19 Gundavda MK, Gundavda KK. Cancer or COVID-19? A review of guidelines for safe cancer care in the wake of the pandemic. SN Compr Clin Med 2020;2:2691-2701

20 Miyashita H, Mikami T, Chopra N, et al. Do patients with cancer have a poorer prognosis of COVID-19? An experience in New York City. Ann Oncol 2020;31(8):1088-1089

21 Battisti NML, Mislang AR, Cooper L, et al. Adapting care for older cancer patients during the COVID-19 pandemic: recommendations from the International Society of Geriatric Oncology (SIOG) COVID-19 Working Group. J Geriatr Oncol 2020;11(8):1190-1198 